\title{
O NORMAL ESTÁ RELACIONADO A UMA PERCEPÇÃO INDIVIDUAL DE ACORDO COM A PERSONALIDADE
}

\author{
THE NORMAL IS RELATED TO AN INDIVIDUAL PERCEPTION ACCORDING \\ TO PERSONALITY
}

Fabiano de Abreu Rodrigues ${ }^{1}$

RESUMO: Ao caracterizar um indivíduo como normal, queremos dizer que ele pode apresentar características como aparência e comportamento que sejam padrão para a maioria da população daquela sociedade, tornando-se alguém socialmente aceitável aos padrões. Essas pessoas agem segundo o padrão de normalidade, sem chamar a atenção para suas vestimentas, gosto musical, pois apresentam características que o fazem se tornar comum e igual ao seu grupo. Sendo assim, o objetivo do presente estudo foi compreender o conceito de normalidade e se percepção individual está relacionada à personalidade. Trata-se de uma revisão de literatura no portal de periódicos eletrônicos da SciELO, PubMed PsycINFO e Science Direct. Sendo assim, ser normal depende de diversos aspetos sociais e culturais, pois o que pode ser normal para um pode não ser para outro. Estando assim, demonstrando uma relação da perspectiva individual, permanecendo de acordo com a personalidade.

Palavras-chave: Normalidade. Personalidade. Neurociência.

ABSTRACT: An individual is normal, we mean that he can present characteristics such as appearance and behavior that are standard for the majority of the population, becoming something that is socially acceptable and common. Such people act according to the standard of normality, without drawing attention to their clothing, musical taste, as they have characteristics that make them common and equal to their group. Thus, the aim of this study was to understand the concept of normality and whether individual perception is related to personality. This is a literature review on the SciELO electronic journal portal, PubMed PsycINFO and Science Direct. Therefore, being normal depends on several social and cultural aspects, as what may be normal for one person may not be for another. Thus, demonstrating a relationship from the individual perspective, remaining in accordance with the personality.

Keywords: Normality. Personality. Neuroscience.

\footnotetext{
I $\mathrm{PhD}$, neurocientista, neuropsicólogo, biólogo, historiador, antropólogo - Centro de Pesquisas e Análises Heráclito - Castelo de Paiva - Portugal. E-mail: deabreu.fabiano@gmail.com.
} 


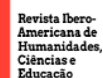

Revista Ibero- Americana de Humanidades, Ciências e Educação- REASE

open 2 access 


\section{INTRODUÇÃO}

\section{Normalidade}

Quando dizemos que um determinado indivíduo é normal, queremos dizer que ele pode apresentar características como aparência e comportamentos que sejam padrão a maioria da população, tornando-se algo socialmente aceitável e comum (Richards et. al., 2015).

Tais pessoas agem segundo o padrão de normalidade, sem chamar a atenção para suas vestimentas, gosto musical; apresentam características que o fazem se tornar comum e igual ao seu grupo (Richards et. al., 2015).

Tornando assim, a minoria que se veste e se comporta de maneira diferente da maioria; ouvem músicas não populares, dentre outras coisas, serem considerados estranhos quando comparado aos indivíduos "normais" padrões (Richards et. al., 2015).

Antes do surgimento da Psicanálise por Sigmund Freud (1856-1939), era bastante discutido este assunto, porém os estudiosos não conseguiam estabelecer um consenso. Quando foi definido que as pessoas padrões que se inserissem em um padrão comum da época em relação à sua cultura seriam normais e aqueles que não seguissem eram denominados como loucos (Widlöcher et. al., 2010).

Quando Freud surge, ele expressa que a normalidade seria uma ficção ideal onde cada ego aproxima-se daquele de um psicótico em grau maior ou menor. Outros pesquisadores tentaram entender tal fato, porém chegando à conclusão de que a normalidade absoluta não existe. Para ele, essas ideias são individuais, para cada ego (Widlöcher et. al., 2010).

Foram aceitos como normais para a sociedade, indivíduos que seguissem as regras sociais ou culturais como parâmetro de normalidade daqueles considerados anormais ou loucos (Widlöcher et. al., 2010).

\subsection{Personalidade}

A personalidade é definida como o agrupamento de características que determinam os padrões pessoais e sociais de um indivíduo, sua formação é um 
processo gradativo e único. No senso comum, a personalidade é utilizada para caracterizar as características marcantes de uma pessoa (Schmitt et. al., 2017).

Sendo relacionada às mudanças de habilidades, atitudes, crenças, emoções, desejos e ao modo constante e particular de cada um (Schmitt et. al., 2017).

Existem diversas teorias que estudam a personalidade, sendo a mais popularizada a de Freud (Schmitt et. al., 2017).

Para Freud, a personalidade é consequência de três sistemas: Id, Ego e Superego. O Id é inato, cada indivíduo nasce com ele, regido por seu prazer próprio e satisfação imediata de seus impulsos. O Ego, é a evolução do Id, pois apresenta características mais conscientes e pré-conscientes, sendo assim são comandados pela realidade. O Superego é derivado de valores familiares e sociais, está relacionado aos sentimentos de punição, medo e culpa (Schmitt et. al., 2017).

Já para Carl Jung existem quatro funções psicológicas básicas: pensar, sentir, intuir e perceber. Cada indivíduo, possuí em graus diferentes cada uma dessas funções (Springer et. al., 2012).

A partir das quatro funções básicas, Jung aponta que se formam dois grandes tipos de caráter: o introvertido e o extrovertido. Contendo características exclusivas. $\mathrm{O}$ tipo extrovertido caracteriza-se por possuir interesses, foca-se primeiramente na realidade exterior e só depois se foca no mundo interior (Springer et. al., 2012).

As decisões são feitas imaginando a realidade exterior, ao invés da realidade. Por exemplo: ações realizadas em função do que os outros possam pensar sobre si mesmo; ética e a moral são construídas de acordo com o que predomina no mundo, se encaixam em quase qualquer ambiente, porém possuem dificuldade em realmente se adaptar, são sugestionáveis, influenciáveis e tendem a imitar os demais, precisam que reparem neles e que sejam reconhecidos pelos outros (Springer et. al., 2012).

Em contrapartida, o tipo introvertido possui diferentes características: interesse por si mesmo, pelos seus sentimentos e pensamentos, orienta o seu comportamento de acordo com o que sente e pensa, mesmo que isso vá contra a realidade exterior, não se preocupa muito com o efeito que as suas ações possam causar ao seu redor (Liou et. al., 2018).

No entanto, segundo Jung existem os oito tipos de personalidade. São eles: 
Reflexivo extrovertido; aqueles de personalidade cerebrais e objetivos, atuando na maioria das vezes por meio da razão. Reflexivo introvertido; são indivíduos com grande atividade intelectual e possuem dificuldade de se relacionar com os demais (Liou et. al., 2018).

Sentimental extrovertido; indivíduos de maior habilidade para compreensão dos demais, afim de estabelecer relações sociais com os indivíduos. Sentimental introvertido: são pessoas solitárias, possuem dificuldade de se relacionar. Perceptivo introvertido: geralmente os artistas possuem tal personalidade; as pessoas perceptivas introvertidas colocam uma ênfase especial nas experiências sensoriais: dão muito valor à cor, à forma, à textura. Intuitivo extrovertido: são pessoas aventureiras, ativas e inquietas, necessitam de estímulos diferentes. Determinados a conseguir alcançar seus objetivos, passando de um para o próximo. Intuitivo introvertido: são pessoas muito sensíveis, aos estímulos mais sutis. São aqueles que "adivinham" o que os outros pensam, são criativas, sonhadoras e idealistas (Liou et. al., 2018).

\section{Objetivo}

Compreender o conceito de normalidade e se percepção individual está relacionada à personalidade.

\section{Metodologia}

Trata-se de uma revisão de literatura no portal de periódicos eletrônicos da SciELO, PubMed PsycINFO e Science Direct. Sendo utilizado os seguintes termos para realização da busca de dados em português: neurociência, normalidade, personalidade e em inglês: neuroscience, normality, personality.

\section{Resultados}

Perugini et. al. (2021), realizou um estudo com o objetivo de identificar a personalidade normal e mal adaptativo da população em geral que fizessem uso de sites de mídias sociais. Sendo assim, a amostra foi constituída por 420 indivíduos (2II homens, 209 mulheres), com idade média de 40, 29 anos. Os dados foram coletados 
usando o Big Five Inventory, o Personality Inventory for DSM-5-Brief Form -Adult, o Mental Health Continuum-Short Form e uma escala projetada ad hoc para avaliar os motivos para o uso de sites de mídia social.

Demonstrando que os traços de personalidade normais e mal adaptativos, são demonstrados perante ao sexo e a idade. Os indivíduos com personalidade de comportamentos mal adaptativos demonstram motivos do uso das redes sociais como passatempo e exibicionismo, diferentes dos considerados normais que estão nas redes por relacionamento pessoal e busca de informações (Perugini et. al., 202I)

O objetivo do estudo de Cicero, et. al. (2019), é entender a relação entre a personalidade normal e de indivíduos com transtornos mentais para identificar suas relações com os sintomas da esquizofrenia e a taxonomia da personalidade.

Examinando assim a estrutura fatorial conjunta dos grupos sendo 288 indivíduos com transtornos psicóticos e 277 adultos nunca psicóticos.

$\mathrm{Na}$ avaliação das estruturas dos traços esquizotípicos (esquizotipia positiva, esquizotipia negativa e desconfiança) e normais, determinados em 5 fatores: neuroticismo, extroversão, conscienciosidade, amabilidade e psicoticismo. Demonstrando que os sintomas de psicose, esquizotipia e personalidade normal refletem as mesmas dimensões subjacentes em ambos os grupos. Demonstrando uma pequena normalidade nos padrões de psicose (Cicero et. al., 2019).

Indivíduos que não possuem medo de expor suas opiniões com sinceridade, sendo essas diferentes da opinião da maioria e sem se importarem, sendo taxados de loucos. Para esses indivíduos eles são normais, pois vivem a realidade deles (Sutherland et. al., 2019).

Sendo assim, ser sincero é uma ótima qualidade, desde que o indivíduo tenha bom senso na hora de usá-la, para não magoar outras pessoas e não ser taxado de louco. Existem indivíduos que sentem dificuldade em compreender até onde é possível ser sincero, pois pode acabar prejudicando suas relações pessoais e de trabalho (Brotto et. al., 2021).

Em contrapartida os cientistas considerados, pessoas super inteligentes, por muitas vezes são taxados de loucos em sua maioria. Por exemplo o engenheiro Nikola Tesla, que não tocava em cabelos, brincos de pérola ou qualquer coisa 
redonda, era obcecado com o número 3 . E em cada refeição, ele usava exatamente 18 guardanapos para polir os utensílios até que brilhassem (Guinovart et. al., 2020).

O matemático e engenheiro eletricista britânico Oliver Heaviside, famoso por desenvolver técnicas matemáticas. Ficou conhecido como louco, pois pintava suas unhas com cor rosa, bebia apenas leite por vários dias, hábitos que eram considerados anormais para a época (Guinovart et. al., 2020).

O físico Albert Einstein, é popularmente chamado de louco, pois tinha hábitos um tanto distintos como se deitar na banheira vazia para estudar, dormia cerca de io horas por dia e não usava meias de maneira alguma, dentre outras manias, consideradas anormais. Steve Jobs inventor, empresário e fundador da empresa Apple Inc. tinha mais de roo modelos de calças jeans azuis e colecionava roo suéteres idênticos (Luraschi et. al., 2012).

$\mathrm{O}$ arquiteto e cientista Buckminster Fuller, usava três relógios que mostravam o tempo em vários fusos horários quando voava por todo o mundo, e passou anos a dormir apenas duas horas por noite. Tinha um diário detalhado que ele atualizava de 15 em 15 minutos, resultando em pilhas de 82 metros de altura, atualmente encontra-se na biblioteca da Universidade de Stanford (Luraschi et. al., 2012).

\section{Considerações finais}

Sendo assim, ser normal depende de diversos aspetos sociais e culturais, pois o que pode ser normal para um pode não ser para outro, demonstrando uma relação da perspectiva individual, permanecendo de acordo com a personalidade.

Em uma sociedade em que a ansiedade é constante e potencializada, surgem perturbações derivadas de disfunções no sistema límbico do cérebro que alteram o comportamento e como consequência a personalidade. O padrão de ética e moral é determinante para a adaptação social e reconhecimento como componente dentro dos padrões normais da sociedade atual.

Em um mundo globalizado onde determinou-se que ser diferente é legal; muda-se então o conceito de normalidade sendo este evidenciado no comportamento psicológico. Pessoas com comportamento bizarros para um padrão psicológico 
normal, com oscilações emocionais, atitudes incoerentes ou qualquer comportamento que foge à tangente da inteligência, é considerado anormal. A normalidade está definida na lógica, no que é coerente mediante a um padrão psicológico.

Mas há também a anormalidade mediante à coerência; numa sociedade de mídia social, onde as pessoas demonstram ser o que não são potencializando a felicidade. A sinceridade encontra-se em escassez e quando o indivíduo mostrar-se sincero e lógico, mediante à racionalidade com base científica, histórica e estatística; se diferente do padrão que a sociedade camuflada determina, este é visto como um louco. Diversos génios da história foram vistos como anormais antes que fossem comprovadas suas teorias; isso se dá pelo padrão da personalidade rara, de cérebros cuja evolução do córtex pré-frontal não permite que o sistema límbico emocional distorça a coerência. Como o cérebro reptiliano, região do sistema límbico do cérebro, é quem influencia pela sua relação com o instinto, logo uma maioria que se considera normal pode anormalizar os que, por sua vez, tem a personalidade de quem com a lógica encontra a coerência e ao se expressar é visto como anormal.

\section{Referências}

Brotto, T. (202I) Sinceridade: Limite e Excesso. Psicologo e terapia

Cicero, D.C., Jonas, K.G., Li, K., Perlman, G., \& Kotov, R. (2019) Common Taxonomy of Traits and Symptoms: Linking Schizophrenia Symptoms, Schizotypy, and Normal Personality. Schizophr Bull. 24(4),1336-1348, doi: I0.1093/schbul/sbzoo5.

Guinovart, J.J., \& Arimon, M. (2020) Scientists in education: A biomedical research institute's perspective. Biochem Mol Biol Educ. 48(6),559-562, doi: 10.1002/bmb.21344.

Liou, M., Hsieh, J.F., Evans, J., Su, I.W., Nayak, S., Lee, J.D., \& Savostyanov, A.N. (2018) Resting heart rate variability in young women is a predictor of EEG reactions to linguistic ambiguity in sentences. Brain Res. 15 (I70I), II-I7 doi: I0.1016/j.brainres.2018.07.009.

Luraschi, M., Rezzonico, R., \& Pellegri, G. (2012) The chemist, that madman! How children perceive science. Chimia (Aarau). 66(II), 820-825 doi: I0.2533/chimia.2012.820. 
Perugini, M.L.L, \& Solano, A.C. Normal and Maladaptive Personality Traits as Predictors of Motives for Social Media Use and Its Effects on Well-Being. Psychol Rep. I24(3),I070-I092, 202I doi: Io.1177/o033294120922495.

Richards, D., Caldwell, P.H., \& Go, H. (2015) Impact of social media on the health of children and young people. J Paediatr Child Health. 5I(I2), II52-II577 doi: Io.IIII/jpc.13023.

Schmitt, D.P., Long, A.E., McPhearson, A., O'Brien, K., Remmert, B., \& Shah, S.H. (2017) Personality and gender differences in global perspective. Int J Psychol. (I),4556, doi: $10.1002 /$ ijop.12265.

Springer, I.N., Wiltfang, J., Kowalski, J.T., Russo, P.A., Schulze, M., Becker, S., \& Wolfart, S. (2012) Mirror, mirror on the wall...: self-perception of facial beauty versus judgement by others. J Craniomaxillofac Surg. 40(8),773-776 doi: I0.1016/j.jcms.2012.02.007.

Sutherland, M.E. (2019) People are honest after all. Nat Hum Behav. 3(8),779, doi: 10.1038/s41562-019-0713-4

Widlöcher, D. (2010) Distinguishing psychoanalysis from psychotherapy. Int J Psychoanal. 9I(3), 45-50 doi: I0.11II/j.1745-8315.2009.00233.x 